\title{
Erratum to: Echocardiography and cardiac resynchronization therapy, friends or foes?
}

\author{
W.M. van Everdingen ${ }^{1} \cdot$ J.C. Schipper ${ }^{1} \cdot$ J. van 't Sant ${ }^{1} \cdot$ K. Ramdat Misier ${ }^{1}$. \\ M. Meine ${ }^{1} \cdot$ M.J. Cramer ${ }^{1}$
}

Published online: 17 February 2016

(C) The Author(s) 2016. This article is published with open access at Springerlink.com

\section{Erratum to: Neth Heart J (2016) 24:25-38 \\ DOI 10.1007/s12471-015-0769-3}

Figures 3 and 4 and the captions of figures 2, 3, and 4 in the original article were incorrect and should have appeared as presented in this erratum. The editors apologise for this oversight and any confusion this may have caused.

The online version of the original article can be found under doi:10.1007/s12471-015-0769-3

\footnotetext{
W.M. van Everdingen

w.m.vaneverdingen@umcutrecht.nl

Department of Cardiology, University Medical Centre

Utrecht, Heidelberglaan 100, 3508 GA PO Box 85500,

Utrecht, The Netherlands
} . 

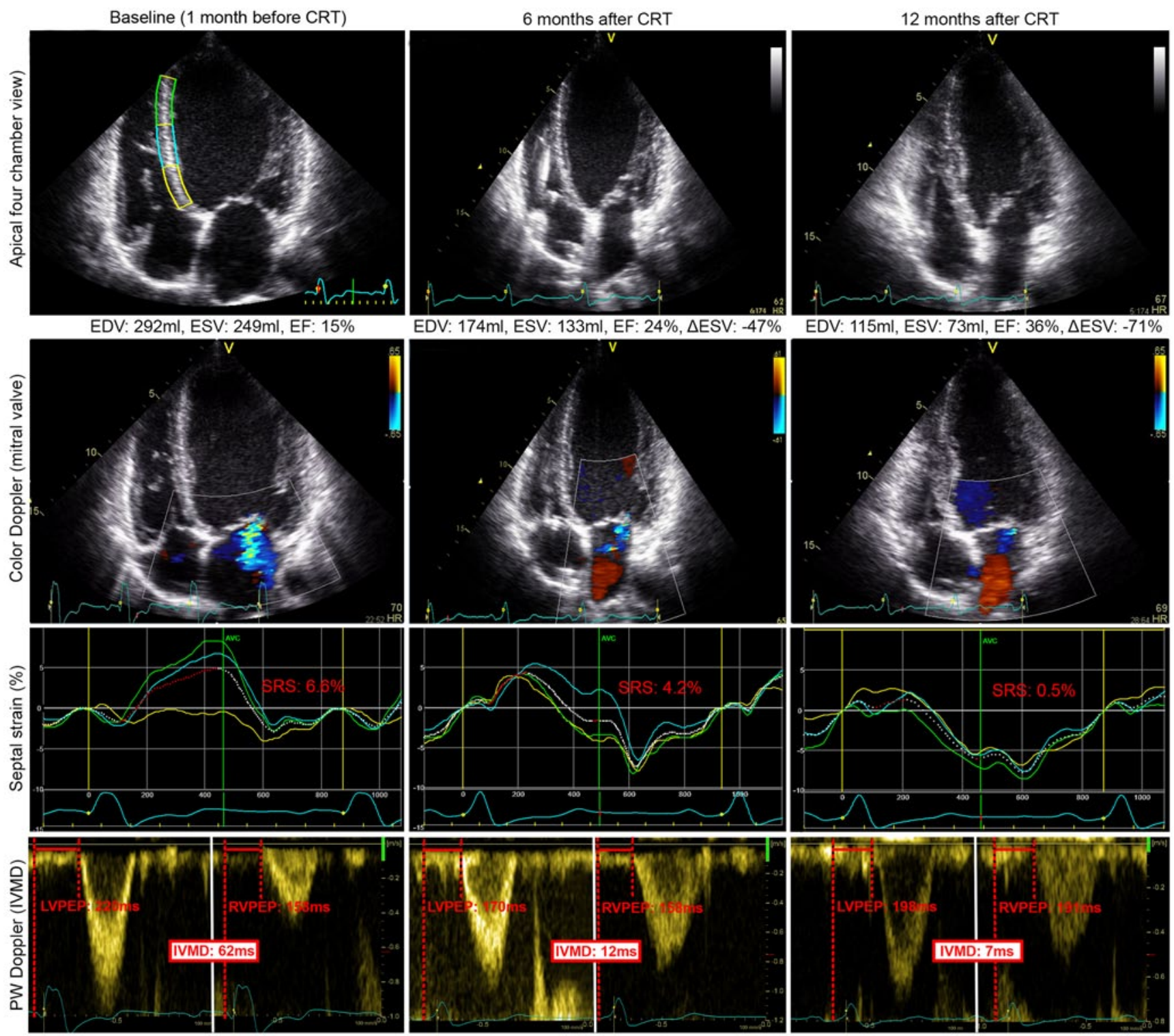

Fig. 3 Example of echocardiographic data obtained from a responder to CRT. Apical four chamber view, colour Doppler, septal strain and pulsed-wave Doppler acquisition of a responder to CRT, before, and 6 and 12 months after implantation. Note the continuous decrease in LV volume, decrease in mitral regurgitation, improvement in septal strain and decrease in IVMD over time. These data suggest a continuous process of reverse remodelling. Septal strain: yellow, light blue and green lines represent basal, mid and apical inferoseptal segmental strain, respectively. The three curves represent the segments illustrated in baseline echocardiogram in the upper left panel. The white dashed curve represents the average septal strain. SRSsept is marked red, as all rebound stretch after initial shortening, during systole. IVMD is represented by PW-Doppler signals of the left and right ventricular outflow tract. $E D V$ end-diastolic volume, $E S V$ end-systolic volume, $E F$ ejection fraction, $\triangle E S V$ change in ESV compared to baseline, $S R S$ systolic rebound stretch, $L V P E P$ left ventricular pre-ejection period, $R V P E P$ right-ventricular pre-ejection period, IVMD inter-ventricular mechanical delay. Volumes are derived by biplane Simpson method. 

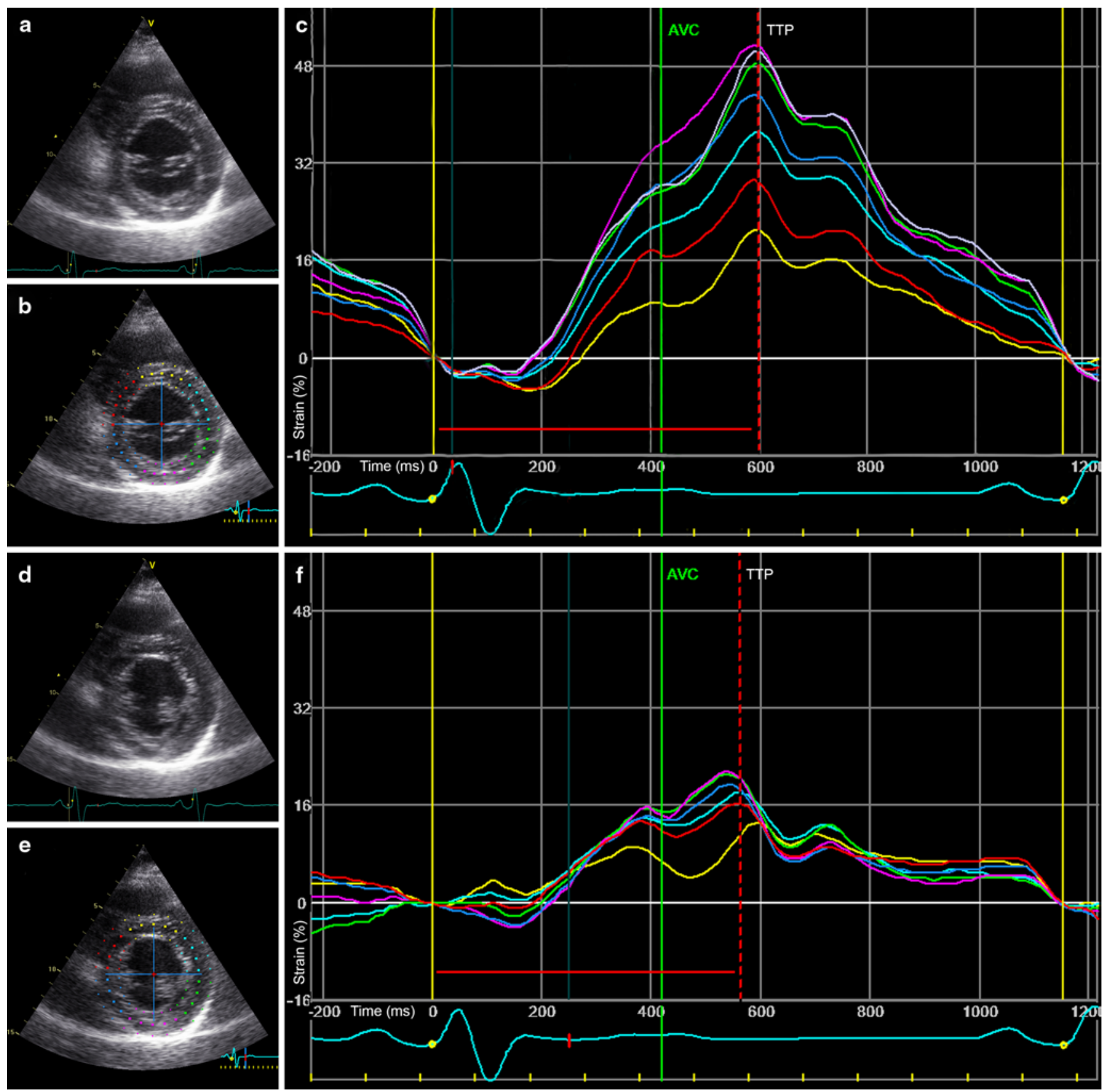

Fig. 4 Radial strain analysis of parasternal short axis images. Parasternal short axis (PSAX) views and radial strain analysis of a patient with LBBB, imaged prior to CRT implantation. LV lead placement resulted in a mid-posterolateral position (green curve in Fig. 4f). ESV decrease after 6 months of therapy was $49 \%(88-43 \mathrm{ml})$. a \& d B-mode images with excellent echocardiographic quality of PSAX mitral valve level and papillary muscle level. $\mathbf{b} \&$ e region of interest (ROI) placement for radial strain analysis of both PSAX views. c \& $\mathbf{f}$ strain curves of corresponding ROIs; note the similarity in time-to-peak strain. There is no single area with latest activation. 
